filtrate of whole blood, as was the amino-nitrogen. The former determination was done by the method of Folin and Wu (1919), and the latter by van Slyke's method (1929). Blood cholesterol levels were determined by Leiboff's method (1924), the blood proteins by Andersch and Gibson's (1933) modification of Wu and Ling's method: Urinary nitrogen was determined by the Kjeldahl method, and the creatinine and "total creatinine" by the colorimetric method of Folin (1914). The total sulphates (inorganic plus ethereal sulphates) were estimated by the method of Folin (1905). Some difficulty was experienced in obtaining consistent results in total sulphur estimations until a method after Pirie (1932) was used. Estimations on each individual sample were repeated until a constant value was obtained. To check these results a pooled sample made from proportional parts of each daily sample was prepared and the sulphur content estimated. The final value obtained from the pooled sample was within $2 \%$ of the sum of the values from the individual samples.

\section{Comment on Laboratory Investigations}

The first abnormality revealed by the routine investigations was the rise in the serum bilirubin level between 12.30 p.m. and 6.30 p.m. on Oct. 3-i.e., during the period when the liver was enlarging rapidly. Apart from' the rise in blood aminonitrogen at the end of the period of infusion and the transient appearance of urobilinogen on the day when relapse occurred, the routine investigations showed no other significant abnormality. It is of interest to note that the serum bilirubin on Nov. 2 had remained at the same level as on the day before discharge (Oct. 13).

In addition to these routine tests an attempt was made to follow the mode of action of methionine by estimating the nitrogen and sulphur balances of the patient and by determining the partition of the urinary sulphur between the oxidized (total sulphate) and unoxidized (neutral) fractions. It would appear from the balance figures that there was a nitrogen retention of $6 \mathrm{~g}$. over the whole period. This may well be accounted for by nitrogen loss in the faeces. It should be noted, however, that on the 3rd and 4th there was a total negative balance of $7 \mathrm{~g}$., which was almost eliminated by the sum of the positive balances of the 5th and 6th. While it is difficult to believe that the negative balance represents the rapid destruction of cellular elements followed by an equally rapid replacement, it may well be that on the 3rd and 4th the processes of protein synthesis in the liver were impaired, but returned to normal on the 5th and 6th and continued so during the rest of the period of observation.

The positive sulphur balance is, however, proportionately much greater. Even when a $5 \%$ error in estimated intake a faecal loss of $10 \%$, and an error of $2 \%$ in the total urinary sulphur estimations are deducted from the positive balance, there is still a small amount of sulphur unaccounted for. Since it is unlikely that all these factors operate at a maximum value and in the same direction the retention of sulphur is probably significant.

That the liver damage was in the nature of a metabolic derangement rather than an actual destruction of liver substance is indicated by the partition of the urinary sulphur. We have not yet followed the metabolism of large quantities of methionine given intravenously to normal individuals. Medes (1937), however, has shown that of $3.2 \mathrm{~g}$. of $d l$-methionine given orally to normal individuals $95 \%$ is oxidized to sulphate and excreted in the urine within 24 hours, causing no appreciable rise in the unoxidized sulphur fraction. As it has also been shown by Martin and Thompson (1943) that aminoacids injected at the rate of $10 \mathrm{~g}$. an hour do not spill over into the urine, it is safe to assume that a normal individual receiving the same treatment as our patient would have excreted in the urine the major portion of the methionine sulphur as oxidized (total sulphate) sulphur within 24 hours. The rate of injection of the solution used in our patient was almost identical with that quoted by Martin and Thompson. Our patient, however, excreted an excessive amount of unoxidized sulphur during the first two days, a quantity which was roughly equivalent to $65 \%$ of the amount of sulphur given therapeutically as methionine. While there is a possibility that some of the unoxidized sulphur excreted on the first day might be due to spill-over into the urine, this cannot be true of that excreted on the second day. Moreover, a similar phenomenon was noted on the day of relapse, when the methionine was given orally. Thereafter the neutral sulphur fraction was within the usually accepted normal limits.

These considerations lead us to believe that the intimate cause of the liver disturbance induced by carbon tetrachloride is an abnormal metabolism of methionine and related compounds, and, moreover, that in our patient it was specifically the administration of methionine which prevented further liver damage. We hope to be able to determine the degree of permanent liver damage, if any, and the patient's reponse to large doses of methionine when he is readmitted to hospital for investigation at the end of six months.

The history of a case of acute carbon tetrachloride poisoning has been presented.

The patient was treated successfully by $d l$-methionine administered partly by infusion and partly by mouth.

An attempt has been made to follow the metabolism of the methionine administered.

We wish to express our thanks to Col. Middleton and Col. Hatcher, U.S. Army Medical Corps, for putting hospital and laboratory facilities in a U.S. Military Hospital at our disposal. We are grateful to Dr. M.. Smith and Miss W. Watts for their assistance with the laboratory investigations, to Miss Eisendorff for superintending the dietetic work, and to the ward and laboratory staffs for their co-operation. We wish to thank the Research Department of British Colloids Ltd. for providing generous samples of casein digests suitable for intravenous injection.

\section{REFERENCES}

Andersch, M., and Gibson, R. B. (1933). J. lab. clin. Med., 18, 816. Folin, O. (1905). J. biol. Chem., 1, 131 . (1914). Ibid., 17, 469

- and Wu, H. (1919). Ibid., 38, 81.

Gibson, R. B., and Goodrich, G. E.'(1934). Proc. Soc. exp. Biol., N.Y., 37, 413 Leiboff, S. L. (1924). J. biol. Chem., 61, 177 .

cCance, R. A., and Widdowson, E. M. (1940). Med. Res. Cncl. Sp. Rep. Ser. No. 235 .

Martin, G. J., and Thompson, M. R. (1943). Medicine, 22, 73.

Medes, G. (1937). Biochem. J., 31, 1330.

Miler, L. L., and Whipple, G. H. (1942). J. exp. Med., 76, 421

van Slyke, D. D. (1929). J. biol. Chem., 83, 425.

\section{A Clinical EVAlUation OF SOME TESTS OF LIVER FUNCTION}

BY

G. HIGGINS and J. R. P. O'BRIGN

Department of Biochemistry, University of Oxford

ALICE STEWART AND L. J. WITTS

Nuffield Department of Clinical Medicine

(Radcliffe Infirmary, Oxford)

Before biochemical tests are accepted for the diagnosis or assessment of disease of the liver in man they should conform to certain conditions. First, it is essential to know the extent of the normal variations. To do this the tests must be applied to a large number of healthy men and women of different ages. Secondly, the tests should be applied in proved disease of the liver to show their sensitivity. 'To be satisfactory the results should differ materially from those found in the normal series. Detailed analysis might also reveal points by which one could distinguish between the various forms of liver disease and judge the severity of the liver damage. Thirdly, the tests should be applied in other diseases to show how specific they are.

Only when tests have been considered from these standpoints can they justifiably be applied to unselected clinical material. Although obvious, these criteria have often been ignored in the past, and even now are not fully appreciated. The number of observations on control casès is often small, and the worth of the tests in the diagnosis of disease of the liver is often open to doubt. Applied to cases in which the diagnosis is uncertain, they have given abnormal findings which have led to the assumption that the patient is suffering from disease of the liver. Then, by a familiar logical fallacy, it 
is argued that the tests are good tests because they have revealed disease of the liver. In the work here presented a determined effort has been made to break this vicious circle and to put the first two conditions of validation on a sound statistical basis. Final proof 'of the exact specificity of the tests would include repeating them in every known disease. This is clearly impossible, but the tests have been done in a large group of miscellaneous diseases.

The biochemical investigations reported here are part of a much larger study of pigment metabolism (O'Brien, 1944), and only those immediately concerned with liver function are given. These are attempts to assess the efficiency of the liver in performing certain biochemical activities ascribed to it, and include tests to demonstrate the part it plays in carbohydrate metabolism and protein synthesis, and its ability to secrete, excrete, and detoxify certain organic compounds. The following estimations were made:

Plasma Bilirubin : Colorimetric (Thannhauser and Andersen, 1921)

Plasma Phosphatase : Colorimetric (King and Armstrong, 1934)

Plasma Proteins : Micro-Kjeldahl (Howe, 1921)

Hippuric Acid Test : Titration (Probstein and Londe, 1940)

Modified Laevulose-tolerance Test : Colorimetric (Higgins, O'Brien, and Stewart, 1942). The laovulose index is derived from this test.

100 individuals -50 males and 50 females between the ages of 18 and 50 years, all university students or laboratory personnel-were used as controls.

\section{Diseases of the Liver}

The patients studied comprised all suitable cases of disease of the liver admitted to the Radcliffe Infirmary during the past three years. Many of the patients were kept under continuous observation, and the tests were repeated during the course of the illness. The others were made the subject of a special follow-up investigation in the summer of 1943. Several of the patients who had recovered were re-examined some months after their discharge from hospital. Biochemical data were completely disregarded in making the diagnosis, which was founded on clinical criteria. The following diseases are represented:

Secondary Carcinoma of the Liver (16 Cases).-The diagnosis was confirmed either at operation or at necropsy. For the purpose of statistical analysis two groups are recognized-one with intense jaundice due to extrahepatic obstruction ( 9 cases), and one in which there was no compression of the large bile ducts ( 7 cases).

Acute Hepatitis (22 Cases).-These were all cases of acute parenchymatous disease of the liver in which the illness was of short duration. Fifteen were probably cases of infective hepatitis, and one developed jaundice after an operation for appendicitis and intensive sulphonamide therapy. There were three cases of post-arsphenamine jaundice, two cases of Weil's disease, one of which was fatal, and one fatal case of acute hepatitis of unknown aetiology. Post-mortem examination in the two fatal cases showed acute diffuse hepatitis with no residual scarring.

Subacute Hepatitis (19 Cases).-These were cases of hepatitis with jaundice in which the illness lasted longer than two months. In every instance jaundice was the presenting sign, and investigation excluded the presence of gall-stones or neoplasm. Eight patients died, six showed complete clinical recovery at the time of the follow-up, and five were still suffering from recognizable liver disease. Post-mortem examination was made in all the fatal cases, and revealed massive necrosis with scarring and nodular hyperplasia.

Of the six patients who recovered two were cases of post-arsphenamine jaundice, one had been exposed to T.N.T., and three were probably cases of infective hepatitis.

Three of the eight patients who died had had previous attacks of jaundice, diagnosed at the time as infective hepatitis. One had worked in a laundry and handled trichlorethylene for a number of years. There was no clue to the aetiology in four of the cases.

The five patients who showed progressive disease of the liver but were alive at the time of the follow-up included one who had used carbon tetrachloride as a cleaning agent for many years. He had a mild attack of jaundice while on holiday. He returned to work immediately afterwards, but continued to feel ill, and two months later the jaundice recurred. One patient dated his illness from an attack of jaundice that occurred during an epidemic of infective hepatitis, and he gave a definite history of contact at this time. There was no clue to the aetiology in three of the cases.

Cirrhosis or Chronic Hepatitis (14 Cases).-The onset of the illness in this group was insidious and not marked by any recognizable clinical event. The disease either was discovered accidentally in the course of investigating other conditions or was first seen when symptoms of portal hypertension or terminal liver failure had developed. In every case the liver was inspected either by laparoscopy or laparotomy or at necropsy. One patient gave a history of syphilis and one had haemochromatosis. Both these patients died, and the diagnosis was confirmed post mortem. Three were chronic alcoholics, one of whom also took drugs. One had been treated for epilepsy with Fowler's solution for several years. Six of the fourteen patients died. The tests were repeated in six of the eight who were alive at the time of the follow-up. The essential pathological lesion in the fatal cases was diffuse periportal fibrosis with minimal parenchymatous hyperplasia.

The cases of subacute hepatitis that failed to recover often presented in the later stages of their illness a clinical picture which was indistinguishable from that of cirrhosis. We have used the presence or absence of jaundice early in the disease as the clinical distinction, but it is possible that there is no hard-and-fast line between these two groups. On the other hand, the subacute cases that recovered resembled the cases of acute hepatitis in every respect except that the jaundice was more prolonged. The impression gained from the survey as a whole is that in diffuse hepatitis, as in glomerulo-tubular nephritis, every grade of chronicity exists, but for purposes of classification and statistical analysis the subdivision into acute, subacute, and chronic hepatitis is convenient, and enables one to relate the biochemical abnormalities to the clinical course and prognosis.

\section{Diseases of Other Systems}

Investigations were made in 62 cases of illness other than disease of the liver. The following disease groups were represented :

Anaemia

Secondary

Reticulosis

Thyrotoxicosis

Diabetes

Peptic ulcer

Ascites from other causes Carcinoma

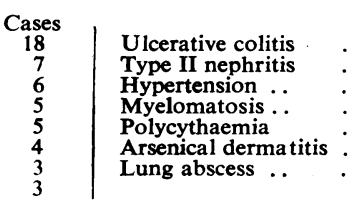

Cases
2
2
2
2
1
1
1

\section{Results}

The results from all three groups are summarized in Table $I$, which gives the mean value and the standard error of the mean for each test. Table II gives a more detailed analysis of the tests in the liver diseases.

\section{Normal Controls}

The complete battery of tests was done on every individual. This is one of the largest control groups for this series of tests yet reported, and should give reliable information regarding the range of values in the healthy adult population living under the wartime conditions of 1942 . The results are being reported in detail elsewhere (Higgins and O'Brien, 1944).

\section{Disease of the Liver}

Plasma Bilirubin.-Both the fatal cases of acute hepatitis were intensely jaundiced. This was also a feature in the early weeks of the illness in the more severe cases of acute and subacute hepatitis that eventually recovered. The last group contained two gravely ill patients in whom the bilirubin was over $20 \mathrm{mg}$. per $100 \mathrm{c.cm}$. when first seen. These bilirubin values cannot properly be compared with the ones found in the cases of subacute hepatitis that failed to recover, because these patients were often not sent to hospital until several months after the jaundice had first appeared. None of the cases of cirrhosis gave a history of a previous attack of jaundice, and even in the terminal stages of this disease a rise in the plasma bilirubin of more than 2 or $3 \mathrm{mg}$. was exceptional. As might be expected, there was intense bilirubinaemia 
in the cases of carcinoma with extrahepatic obstruction, and only moderate jaundice in those in which there was none.

Plasma Phosphatase.-The average value for the plasma phosphatase was above normal in each group. The two fatal cases of acute hepatitis gave values of 18 and 22 units respectively. In the cases of hepatitis that recovered the level of the plasma phosphatase ranged from 10 to 54 units at the height of the illness, with a mean value of 24 units. In every case except one the level returned to normal when the patient recovered. The exception was a boy with subacute hepatitis. His plasma phosphatase was still 35 units six months after the beginning of the illness. Variable results were obtained the thirteen cases in this group had more than $2.8 \mathrm{~g} . \%$ albumin when first seen, and six of the eight fatal cases gave terminal values of less than $2 \mathrm{~g}$. \%. Three of the five cases that were still alive had just over $3 \mathrm{~g}$. \% albumin when last seen.

Low values were also found in the patients with cirrhosis, but three of the fourteen cases had more than $3.5 \mathrm{~g}$. \% albumin when first seen. These three patients were alive and well at the time of the follow-up. Only one patient had less than 2 g. \% albumin, and he died within a month. In both types of carcinoma of the liver the plasma albumin was subnormal, and ranged from 3 to $4 \mathrm{~g}$. \%.

The fall in the plasma albumin was accompanied by a rise in the plasma globulin in many cases of hepatitis. In one of the fatal cases of acute hepatitis and in thirteen of the acute and subacute

TABLE I.-Liver Function Tests in 100 Controls, 71 Cases of Liver Disease, and 62 Cases of Other Diseases

\begin{tabular}{|c|c|c|c|c|c|c|c|c|c|c|}
\hline & & \multirow{2}{*}{$\begin{array}{l}\text { No. of } \\
\text { Cases }\end{array}$} & \multirow{2}{*}{$\underset{\text { (mg./100 c.cm.) }}{\text { Bilirubin }}$} & \multirow{2}{*}{$\begin{array}{c}\text { Phosphatase } \\
\text { (units) }\end{array}$} & \multicolumn{3}{|c|}{$\begin{array}{c}\text { Plasma Proteins } \\
(\text { g. } \%)\end{array}$} & \multicolumn{2}{|c|}{$\begin{array}{l}\text { Hippuric Acid } \\
\text { (\% excretion) }\end{array}$} & \multirow{2}{*}{$\begin{array}{l}\text { Laevulose } \\
\text { Index }\end{array}$} \\
\hline & & & & & Total & Albumin & Globulin & 2 Hours & 4 Hours & \\
\hline $\begin{array}{l}\text { Controls } \\
\text { Liver diseases ... } \\
\text { Other diseases }\end{array}$ & $\begin{array}{l}. \\
\because .\end{array}$ & $\begin{array}{r}100 \\
71 \\
62\end{array}$ & $\begin{array}{ll}0.5 & \pm 0.33 \\
8.4 & \pm \\
0.64 & \pm .46 \\
0.08\end{array}$ & $\begin{array}{cc}8 & \pm 2 \cdot 0 \\
33 & \pm 2.52 \\
12.4 & \pm 1.44\end{array}$ & $\begin{array}{l}7.1 \pm 0.38 \\
6.8 \pm 0.12 \\
6.7 \pm 0.11\end{array}$ & $\begin{array}{l}4.6 \pm 0.29 \\
3.2 \pm 0.09 \\
4.0 \pm 0.08\end{array}$ & $\begin{array}{l}2.2 \pm 0.35 \\
3 \cdot 2 \pm 0.13 \\
2 \cdot 3 \pm 0.09\end{array}$ & $\begin{array}{l}59 \pm 9 \cdot 2 \\
35 \pm 1 \cdot 7 \\
55 \pm 1 \cdot 8\end{array}$ & $\begin{array}{l}88 \pm 6 \cdot 1 \\
62 \pm 1.7 \\
80 \pm 1.4\end{array}$ & $\begin{array}{l}11 \pm 1.15 \\
27 \pm 1.60 \\
13.8 \pm 0.35\end{array}$ \\
\hline
\end{tabular}

In this and the following table the mean values and the standard error of the means are shown for each test. The laevulose index is the sum of the maximum value or blood laevulose plus the value at $2 \frac{1}{2}$ hours after ingestion of $100 \mathrm{~g}$. sucrose.

TABLE H.-Liver Function Tests in 55 Cases of Hepatitis and 16 Cases of Secondary Carcinoma of the Liver

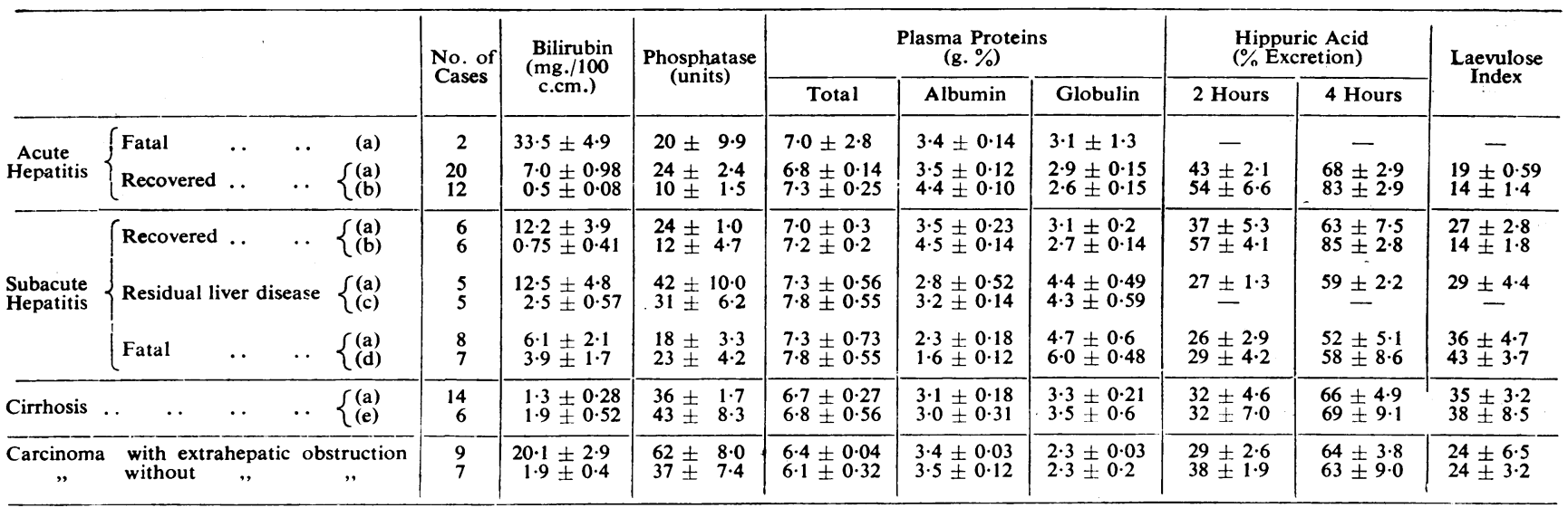

(a) When first seen. (b) After recovery. (c) 3 to 8 months later. (d) Within 1 month of death. (e) 9 months to 2 years later.

in the cases of subacute hepatitis that failed to recover. The average value was 26 units, but there was a wide scatter and no close correlation between the level of the plasma phosphatase and the clinical condition. In six of the thirteen cases it was below 20 units when first seen, and low values were found in the terminal stages of three of the fatal cases. Four cases of cirrhosis gave values of less than 20 units when first admitted, but the average value, 36 units, was much higher than in the other types of hepatitis. When the tests were repeated at the time of the follow-up only one case of cirrhosis gave a value of less than 40 units. In the cases of carcinoma of the liver with extrahepatic obstruction the plasma phosphatase was usually higher than in any other group. It ranged from 20 to 96 units, with an average value of 62 units. In the cases of carcinoma without extrahepatic obstruction the average value was 37 units, with a range from 13 to 80 units.

Plasma Proteins.-Changes in the plasma proteins occurred in each group, and in the cases of hepatitis in which the illness lasted more than two months a close correlation was observed between the fall in the albumin and the extent of the liver damage. Where the latter was greatest, as in the fatal cases of subacute hepatitis, there was also a remarkable rise in the plasma globulin.

The two fatal cases of acute hepatitis had 3.5 and $3.3 \mathrm{~g}$. \% albumin. Twenty of the twenty-four cases of acute and subacute hepatitis that recovered had less than $4 \mathrm{~g}$. \%. Only four had less than 3 g. \%

The plasma albumin was lowest in the cases of subacute hepatitis that failed to recover. It became still lower as the clinical condition deteriorated, but improved during a remission. Only one of cases that recovered the globulin was over $3 \mathrm{~g} . \%$. In spite of this, in eleven cases of acute hepatitis and in four cases of subacute hepatitis that recovered the total protein was less than $7 \mathrm{~g}$. \%.

In the cases of subacute hepatitis with progressive disease of the liver there was usually a remarkable rise in the plasma globulin, which became still greater as the disease advanced. Only one of the fatal cases had less than $3.7 \mathrm{~g}$. \% globulin in the terminal stage of the illness. The increase in the globulin was often responsible for a rise in the total protein, and in seven cases this was over $8 \mathrm{~g} . \%$. The highest globulin values recorded were 7.2 and $7.7 \mathrm{~g} . \%$, the corresponding total protein being 9.2 and $9.8 \mathrm{~g}$. \%.

The rise in the plasma globulin was less striking in cirrhosis than in the fatal cases of subacute hepatitis, but ten patients had over $3.2 \mathrm{~g} . \%$. The total protein was less than $6.8 \mathrm{~g}$. \% in ten cases and over $8.8 \mathrm{~g}$. \% in two cases. The six patients re-examined during the follow-up showed a greater change in the albumin-globulin ratio than was observed when they were first seen.

The globulin was usually not increased in carcinoma. In only one instance was it over $3 \mathrm{~g}$. \%, and in other cases it ranged between 1.7 and $2.4 \mathrm{~g}$. The total protein was less than $6.7 \mathrm{~g}$. \% in every case except one.

Hippuric Acid Excretion.--In each group the average value for the amount of hippuric acid excretion was subnormal, but there was a wide variation in the individual figures and no close correlation between the amount excreted and the severity or duration of the illness. There was no reliable distinction between the different disease groups. The average two-hourly excretion was slightly lower in the cases of cirrhosis and subacute hepatitis with progressive disease of the liver than in the cases of hepatitis that recovered, and lower in the cases of carcinoma with extrahepatic obstruction than in those without, but there was no difference in the average value for the amount excreted in four hours. Hippuric acid excretion 
and laevulose tolerance were not estimated in the two fatal cases of acute hepatitis.

Laevulose Index.-The average level of the blood laevulose during the two and a half hours after taking $100 \mathrm{~g}$. of sucrose was above normal in each group. It was lower in the cases of acute and subacute hepatitis that recovered than in the cases of cirrhosis and subacute hepatitis with progressive disease. There was less individual variation within the groups and a closer correlation with the general clinical condition than was observed in the hippuric acid test. In carcinoma there was no difference between the obstructive and non-obstructive cases, but there was a wider individual variation than in the other groups. In most cases of carcinoma the level was comparable to that found in mild cases of acute hepatitis.

\section{Other Diseases}

The results from this series cannot be discussed in detail, and it is only possible to give the average value for the whole group, in Table I. With the few exceptions mentioned below there were no individual cases which showed a deviation from the normal in more than one test, and this was also true for the average values for each group of diseases. The following abnormalities were recorded:

(i) The average value for the plasma bilirubin in eight cases of haemolytic anaemia was $2 \mathrm{mg}$. per $100 \mathrm{c.cm}$. In three of these and in eight other anaemias the total protein was below $7 \mathrm{~g}$. \%. This was due to a slight fall in the plasma albumin. In no case was there any rise in the globulin.

(ii) A slight rise in the plasma phosphatase was not infrequent. Values over 20 units were found in three of the reticuloses, one case of pernicious anaemia, and one case of thyrotoxicosis.

(iii) The hippuric acid excretion was reduced in both cases of nephritis, and in one case each of myelomatosis, carcinoma, and thyrotoxicosis.

(iv) The laevulose index was below 18 in all but two instances. One was the case of pernicious anaemia mentioned above, and the other was one of the reticuloses in which the liver was involved. It was normal in all the cases of diabetes.

(v) There was a slight fall in the albumin and a rise in the globulin in both cases of myelomatosis and of hypertension, in two of the cases of syphilis, and in one case each of peptic ulcer and diabetes. In addition to the cases of anaemia, the plasma alburnin was less than $4 \mathrm{~g}$. \% in four cases of thyrotoxicosis, three case of peptic ulcer, and in all the cases of carcinoma and nephritis. There was no rise in the plasma globulin in these cases.

\section{Discussion}

The clinical value of biochemical tests is twofold. They may be important in both diagnosis and prognosis because they often give more accurate information about the functional capacity of an organ than can be obtained by clinical methods alone. In the past the need for diagnostic tests in disease of the liver has been overstressed and relatively little attention has been paid to their prognostic importance. In every case of hepatitis one has to ask oneself, "What is the immediate risk to life? Has the liver suffered irreparable damage? If so, what reserve function still exists?" The present analysis of 55 cases suggests that biochemical tests may help to answer some of these questions, and that when used in this way they are of great value to the clinician.

In so far as all the tests gave average values in disease of the liver which differed significantly from normal, and there were only occasional abnormalities in the other diseases, they appear to be acceptable as liver function tests. Closer analysis, however, shows that in hepatitis they are not all equally useful in the different stages of the disease. The plasma bilirubin is a reliable guide to the immediate prognosis in acute hepatitis, but it is of little value in the subacute and chronic forms. The plasma phosphatase and the hippuric acid test often give valuable supporting evidence of liver damage, but they are not reliable enough to be used as individual tests for the purpose of either diagnosis or prognosis. The laevulose index may be unobtainable in acute hepatitis, and it adds nothing to clinical knowledge at this stage. On the other hand, in subacute and chronic hepatitis it is a good index of the degree of liver damage. It is, however, an inconvenient test in clinical practice, as it involves repeated venepuncture.
Disturbances of the plasma proteins are relatively slight in acute hepatitis, but they are the outstanding feature in the subacute and chronic cases. Normal values are fairly rapidly restored if the case recovers completely, but a persistent alteration of the albumin-globulin ratio indicates that the liver has suffered irreparable damage. In chronic hepatitis adequate liver function may be maintained if there is more than $3.5 \mathrm{~g}$. \% albumin, but below this the margin of reserve is poor. A fall below 2 g. \% albumin is of grave significance. Of the eight cases in which this figure was recorded only three survived more than three months, and they had permanent liver damage. In subacute hepatitis with progressive disease of the liver an improvement in the plasma albumin coincides with the clinical remissions. A rise in the plasma globulin is common in all varieties of hepatitis. It was invariably present when there was less than 2 g. \% albumin. With two exceptions the globulin ultimately reached extremely high values in the fatal cases of subacute hepatitis. Table III shows the close correlation that exists between the changes in the plasma proteins, the prognosis, and the length of time that the jaundice persists.

TABLE III-Analysis of 41 Cases of Hepatitis with Jaundice, showing the Correlation between the Duration of the Jaundice, the Prognosis, and the Changes in the Plasma Proteins

\begin{tabular}{|c|c|c|}
\hline & \multicolumn{2}{|c|}{ Duration of Jaundice } \\
\hline & Less than Two Months & Over Two Months \\
\hline 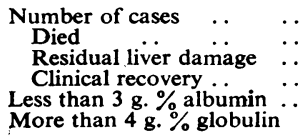 & $\begin{array}{r}22 \\
2 \\
0 \\
20 \\
3 \\
0\end{array}$ & $\begin{array}{r}19 \\
8 \\
5 \\
6 \\
13 \\
10\end{array}$ \\
\hline
\end{tabular}

In the present investigation we have found that a combination of data from the same individual yields more diagnostic information than can be obtained from any single test. The level of the plasma phosphatase is proportional to the level of the bilirubin in jaundice due to biliary obstruction, whereas jaundice that is due solely to haemolysis does not show abnormalities of plasma phosphatase, laevulose tolerance, or hippuric acid excretion. Non-jaundiced cases of cirrhosis that present with ascites or unusual nutritional disturbances are recognized by the disturbance in the plasma proteins and the faulty laevulose tolerance, whereas patients with myelomatosis who have an abnormal albumin-globulin ratio have none of the other changes in the blood chemistry that are found in liver diseases.

The differential diagnosis of subacute hepatitis from obstructive jaundice or carcinoma is often a difficult clinical problem, and laparotomy may be very dangerous. The biochemical data in these cases usually fall into patterns which are easily distinguishable. In subacute hepatitis a moderate rise in bilirubin and phosphatase is accompanied by striking changes in the plasma proteins and a gross reduction in laevulose tolerance. In carcinoma with extrahepatic obstruction the jaundice is associated with a rise in phosphatase; there is usually no change in the plasma globulin, and the laevulose tolerance is not greatly impaired. The changes in carcinoma of the liver without extrahepatic obstruction are the same, except that jaundice is not intense; the phosphatase is still notably raised.

A long and intensive search for specific diagnostic tests in disease of the liver has met with little or no success and has obscured the importance of the changes which occur in the general blood chemistry. Although tests of laevulose tolerance and hippuric acid excretion show abnormal results in disease of the liver, and may be useful when studying the effect on the liver of a potentially toxic substance such as an anaesthetic (Higgins, Macintosh, and O'Brien, 1942), it is doubtful whether in ordinary clinical practice they add much to what can be learnt from a careful study of the blood chemistry. The assessment of liver function is a more practical proposition if it can be performed on a single blood specimen, and it is useful to know that a reasonable estimate can be obtained in this way. 


\section{Summary}

The subjects studied in this investigation were 100 healthy students and laboratory workers, 71 patients with disease of the liver, and 62 patients suffering from other diseases. Every care was taken to establish the clinical diagnosis beyond doubt.

The laboratory tests in all cases included estimations of the bilirubin, phosphatase, albumin, and globulin in the plasma, and measurement of the hippuric acid excretion and laevulose tolerance.

Analysis of the results indicates that a combination of data of this type has considerable diagnostic and prognostic value.

Changes in the plasma proteins in disease of the liver are of great significance. In cases of hepatitis with jaundice there is a close correlation between the time the jaundice has been present, the changes in the albumin-globulin ratio, and the prognosis. Irreparable liver damage has probably occurred if jaundice persists for more than two months or the plasma albumin falls below $2 \mathrm{~g}$. \%. In such cases the plasma globulin is usually over $4 \mathrm{~g} . \%$.

Estimation of the amount of bilirubin, phosphatase, albumin, and globulin in the plasma from a single blood specimen usually provides as much diagnostic and prognostic information as can be obtained from more elaborate tests of liver function.

Full case reports with protocols of the biochemical tests can be obtained from the authors.

We are indebted to the honorary staff of the Radcliffe Infirmary for permission to study their cases, and to Dr. A. H. T. Robb-Smith for doing the necropsies. All the laparoscopies were performed by Dr. A. M. Cooke. Miss M. Stanier, Mr. L. A. Rawlings, and Mr. E. R. Flack helped with the biochemical estimations.

\section{REFERENCES}

Higgins, G., Macintosh, R. R., and O'Brien, J. R. P. (1942). Communication to Physiol. Soc., July, unpublished.

and O'Brien, J. R. P. (1944). In the press.

unpublished. and

Howe, P. E. (1921), J. biol. Chem., 49, 109.

King, E. J., and Armstrong, A. R. (1934). Canad. med. Ass. J., 31, 376.

O'Brien, J. R. P. (1944). In the press.

Probstein, J. G., and Londe, S. (1940). Ann. Surg., 111, 230.

Thannhauser, S. J., and Andersen, E. (1921). Dtsch. Arch. klin. Med., 137, 179

\section{SOME USES FOR DRY COLD THERAPY, AND A PROPOSED COOLING CABINET}

\author{
W. G. BIGELOW \\ Capt., R.C.A.M.C. \\ (A Canadian Casualty Clearing Station) \\ AND \\ E. C. G. LANYON \\ Capt., R.E. \\ (Army Blood Transfusion Service)
}

The therapeutic use of cold has lately been attracting the attention of investigators in many different fields. Recent studies point to the possibility of its much wider employment as a form of treatment in the future. In amputations for diabetic gangrene Allen (1941) and Bancroft et al. (1942) have shown the value of refrigeration as an anaesthetic and demonstrated how it appears to eliminate surgical shock from such a procedure. Its use in retarding the growth and relieving the symptoms of certain malignant tumours was investigated a few years ago by Temple Fay. Several other uses for dry cooling and actual freezing are being studied at the present time.

More important to military surgeons, however, is the steady accumulation of evidence for the value of cold treatment or controlled thawing of lesions of the extremities due to frostbite and immersion in cold water (Webster et al., 1942 ; Greene, 1941, 1942; Ungley, 1943). No attempt will be made to summarize that evidence here. Our purpose is to propose a cooling cabinet for the treatment of such lesions and to encourage the investigation of this form of treatment in three other types of cases: (1) wounds of the extremities which have impaired the blood supply sufficiently to endanger the limb; (2) traumatic arterial spasm; (3) peripheral embolism. The refrigerating unit is specially designed for treating such lesions of the extremities in the field. It is a relatively simple mobile self-contained unit, not dependent on any cooling material that may be difficult to obtain. Observations made on a working model already constructed show that the temperature in the limb cabinet is easily controlled and can be maintained at any desired level.

\section{Frost-bite and Immersion Foot}

Greene (1941), by enumerating high casualty rates in previous military campaigns, has pointed out the serious potential danger of frost-bite in troops operating in cold weather. To quote one instance, he refers to the week ending Dec. 16, 1916, in which 3,104 frost-bitten men were admitted to medical units in the British Army alone. Adequate prophylaxis will prevent most cases of frost-bite, but tactical situations will not always allow the adoption of proper preventive measures, particularly in sudden changes of weather.

The rationale for the cold treatment of frost-bite and that for immersion foot are basically the same. Each is an attempt to reduce cell metabolism until such time as oxygen can be made available to the cell by the blood in sufficient quantity to satisfy the cell requirements at body temperature. In this way an oxygen deficit which would ordinarily cause death of the cell and gangrene of all or part of the extremity is avoided during the time taken for return to normal circulation and cell nutrition in the affected limb.

Webster first used and demonstrated clinically the value of local refrigeration of limbs in immersion foot. Under this treatment pain was relieved, the oedema subsided, blisters disappeared, and impending gangrene was arrested. During the period of exposure there is a vasoconstrictive ischaemia. On removing the limb from cold water and allowing it to thaw he describes a rapid increase in swelling, with pain. This is considered essentially a vascular response to tissue injury in which a liberated $\mathrm{H}$-substance (Lewis, 1941) produces increased permeability of small vessels with resultant transudation into the tissues. Associated with this swelling there is an intense hyperaemia with anaesthesia and anhidrosis lasting several weeks, which, together with a sensitivity to adrenaline in the affected limbs, is evidence of a sympathetic-nerve or vasomotor paralysis (Ungley and Blackwood, 1942; Webster et al., 1942). After the eighth to tenth day paraesthesias develop with later attacks of hyperhidrosis and cold-sensitiveness suggesting a Raynaud's phenomenon (Ungley).

Webster observes that "at the present it is not known how much of the fluid loss from vessels is due to actual damage of the vascular wall and how much is due to loss of neurogenic control of the vessels." The oxygen deficit in these cases he believes is caused by the intense tissue oedema hindering the transfer of oxygen to the cells plus the increased metabolic demand due to the reaction to tissue injury.

Frost-bite, a more serious problem in mobile war, is a condition in which actual freezing of tissues has occurred comparatively rapidly. Here one finds essentially the same pathogenesis, with a few possible differences depending for the most part on the rate of freezing. The swelling is usually not so pronounced. The period of reactive hyperaemia with increased swelling and pain following removal from cold has been personally observed in a few cases to last only a matter of minutes or hours (as compared with several weeks in immersion foot), depending on the severity of the lesions. This is possibly due to a lesser degree of tissue and nerve damage from a shorter period of exposure to thermal injury. Following this transient hyperaemia one sees the early onset of paraesthesia extending up the limb with varying degrees of sweating. A condition of "stasis" or capillary blockage by cells has been observed experimentally by Kreyburg and Rotnes (1932), confirmed by Greene, using a rapid-freezing technique which further increases the anoxia or oxygen deficit in the tissues. (Review of evidence: Bigelow, 1942.)

Thus, as in immersion foot, refrigeration by dry cooling will lower the metabolic demands of the part until normal neurovascular conditions have been re-established.

Webster in treating immersion foot has already used (1) cold air from a fan, (2) ice packs, (3) a cabinet for the feet in which the cooling device is air blown over ice by a fan. Greene (1942) for the treatment of frost-bite has recently devised a cabinet which is cooled by solid carbon dioxide 